\title{
Melhoramento genético da mamona visando incremento de flores femininas
}

\author{
Fernanda Bertozzo ( $\left(^{*}\right)$; Ana Carolina da Costa Lara ('); Maurício Dutra Zanotto $\left(^{2}\right)$ \\ (') Universidade Estadual Paulista "Julio de Mesquita Filho" (UNESP), Faculdade de Ciências Agronômicas (FCA), \\ Programa de Pós-Graduação, Caixa Postal 237, 18610-307 Botucatu (SP). \\ (2) UNESP, FCA, Departamento de Produção Vegetal, 18610-307 Botucatu (SP). \\ (*) Autora correspondente: fbertozzo@yahoo.com.br
}

Recebido: 8/mar./2009; Aceito: 26/set./2010

\begin{abstract}
Resumo
O objetivo deste trabalho foi testar métodos de seleção visando ao aumento de flores femininas na população FCA-UNESPPB de mamona (Ricinus communis L.). A seleção foi realizada no município de Botucatu (SP), na safrinha de 2007. Por meio de seleção massal, foram selecionadas plantas com racemo primário estritamente feminino. Destas plantas, as que tinham reversão sexual foram autofecundadas. As avaliações foram realizadas na safrinha de 2008 em Botucatu e São Manuel (SP), onde foram comparados os tratamentos: método de seleção massal; método de seleção massal com autofecundação e testemunha (racemos de plantas colhidos ao acaso, sem seleção). Foram avaliados: porcentagem de flores femininas do racemo primário (\%), produtividade de grãos ( $\mathrm{kg} \mathrm{ha}^{-1}$ ) e teor de óleo das sementes (\%). O delineamento experimental utilizado foi o de blocos casualizados com 30 repetições. Os dados foram submetidos à análise de variância individual para cada local e conjuntamente para os dois locais, pelo teste F a 1\% de probabilidade. Mediante os resultados conclui- se que o método de seleção massal com autofecundação foi aquele que proporcionou maiores valores de porcentagem de flores femininas no racemo primário, com ganho fenotípico realizado de 18\% em Botucatu e 29\% em São Manuel (SP). Por meio dos métodos de seleção, notou-se comportamento diferencial em relação aos locais para a característica produtividade de grãos, e o método seleção massal com autofecundação proporcionou a menor produtividade. No teor de óleo não houve diferenças significativas entre os métodos e os locais avaliados.
\end{abstract}

Palavras-chave: Ricinus communis L., seleção massal, autofecundação, expressão sexual.

\section{Genetic improvement of castor bean in order to increase female flowers}

\section{Abstract}

The objective of this research was to test selection methods in order to increase female flowers percentage of castor bean plants (Ricinus communis L.) from population FCA-UNESP-PB. Selection of plants was done in Botucatu, State of São Paulo, during the out-of-season crop of 2007. Plants with primary raceme strictly female were selected by the mass selection and plants that presented sex reversion were selfed. Evaluations were taken in out-of-season crop of 2008 in Botucatu and São Manuel, State of São Paulo, when the following treatments were compared: mass selection method; mass selection method with selfing; and control (racemes of plants collected at random, without selection). The traits evaluated were female flowers percentage on primary raceme (\%), grain yield ( $\mathrm{kg} \mathrm{ha}^{-1}$ ) and seeds oil content (\%). The experimental design was in randomized block design with 30 replications. The results were analyzed using analysis of variance of each individual environment and both environments together, by the F test at 1\% probability level. From the results obtained, it is concluded that mass selection method with selfing presented the highest female flowers percentage on primary raceme, with 18\% of phenotypic gain in Botucatu and 29\% in São Manuel, State of São Paulo. The selection methods presented distinguished behavior comparing the two environments for grain yield, with mass selection with selfing presenting the lowest yield. The oil content was not affected by selection methods and environments.

Key words: Ricinus communis L., mass selection, selfing, sexual expression. 


\section{INTRODUÇÃO}

A mamoneira (Ricinus communis L.) é uma espécie oleaginosa pertencente à família das euforbiáceas. O óleo extraído de suas sementes presta-se a uma ampla gama de setores da indústria oleoquímica, sendo considerado um dos mais versáteis encontrados na natureza (BANZATTO e Rocha, 1969; WeIss, 1983).

Trata-se de uma planta monóica que possui como inflorescência-padrão racemos com flores femininas no ápice e masculinas na base, em proporçôes que variam grandemente, entre $30 \%$ e $50 \%$ de flores femininas e $50 \%$ e $70 \%$ de flores masculinas (ClaAsSen e Hoffman, 1949), em decorrência de fatores genéticos e ambientais.

Embora seja considerada uma espécie autógama (TÁVORA, 1982), a mamoneira, em funçâo do seu sistema reprodutivo, tem alta taxa de alogamia, enquadrando-se melhor na classificação de plantas mistas ou intermediárias. Vencosvky et al. (2001) definem uma população mista como aquela que possui taxa de cruzamento entre $5 \%$ e $95 \%$; estes valores representam médias referentes à população, não ao indivíduo. A facilidade na obtenção de cruzamentos e autofecundações controladas na mamoneira a torna uma planta interessante do ponto de vista genético para inúmeros estudos.

Os cruzamentos em plantas de mamona expressam a heterose ou vigor de híbrido, atingindo seu potencial máximo, posto que os híbridos de mamona são mais uniformes e produtivos. Em contrapartida, autofecundaçóes sucessivas realizadas para a obtenção de linhas puras podem levar a planta à depressão por endogamia. A depressão por endogamia é consequência da carga genética da populaçẫo. Uma definiçẫo de carga genética é "o total de todos os genes deletérios e letais que estão presentes em membros individuais de uma população" (GRIFFTHS et al., 2000), ou seja, uma redução geral do desempenho agronômico de plantas quando submetidas a um nível de endogamia maior que a praticada normalmente pela espécie.

Com relação à inflorescência-padrão da mamoneira, além de plantas com racemos monóicos, são observadas na natureza plantas de mamona com o racemo inteiramente coberto por flores femininas; tais plantas são de grande interesse para o melhoramento genético. A obtenção de linhagens femininas é um dos objetivos do melhoramento da mamoneira, pois viabiliza a produçáo de sementes híbridas. Entretanto, a complexidade, a forte influência do ambiente e os restritos estudos genéticos de expressão sexual desta espécie tornam oneroso trabalhar com tal característica em termos de melhoramento.

BeLtrão et al. (2001) afirmam que a biologia floral da mamoneira é bastante complexa, com diversas expressóes de sexualidade. Além das diversas expressões, as plantas de mamona podem ser classificadas em dois grupos: as de desenvolvimento normal ou estáveis, que são plantas monóicas e femininas; e aquelas que nascem femininas e ao longo da ontogenia da planta se revertem, retornando ao monoicismo- padrão, consideradas instáveis (SHIFrIss, 1960). As plantas instáveis possuem herança genética bastante complexa e não totalmente entendida; sabe-se que a característica de instabilidade sexual é de natureza quantitativa e controlada por um sistema poligênico (SHIFRIss, 1955).

O fator ambiental já foi comprovado ser determinante nas variaçôes da expressão sexual da mamoneira. Estudos confirmam que plantas submetidas à deficiência hídrica aumentam sua porcentagem de flores masculinas, assim como altas temperaturas provocam o mesmo efeito. Em contrapartida, solos férteis ou bem balanceados favorecem o aumento da porcentagem de flores femininas (GURGEL, 1945). Beltrấo et al. (2001) afirma que os fatores que afetam a expressão do sexo, aumentando a incidência de flores femininas são: poda, dias curtos, plantas jovens e racemos primários, que têm maior quantidade de flores femininas. Em contrapartida, temperaturas elevadas favorecem a ocorrência de maior número de flores masculinas. Essas informaçóes são importantes do ponto de vista do melhoramento genético, pois mostram que para a seleção visando ao incremento de flores femininas no racemo de plantas de mamona, o ambiente de cultivo é de grande influência.

O material genético utilizado no desenvolvimento deste trabalho foi a população FCA-UNESP-PB (porte baixo) de mamona, com características desejáveis para a colheita mecanizada, como porte baixo, precocidade e frutos indeiscentes. A escolha do material foi feita com base na existência de variabilidade para a característica de expressão sexual, a qual já foi relatada por Mүсzкоwsкi (2006) que selecionou plantas com racemos 100\% pistilados na população em estudo, podendo esta característica ser melhorada com a seleção, favorecendo a porcentagem de flores femininas nos racemos. Portanto, o objetivo deste trabalho foi testar métodos de seleção visando ao aumento de flores femininas na populaçáo FCA-UNESP-PB de mamona (Ricinus communis L.) e verificar se a seleção para a característica de feminilidade interfere nas características de interesse agronômico para a mamoneira, como produtividade de grãos e teor de óleo da semente.

\section{MATERIAL E MÉTODOS}

O material utilizado no presente trabalho constituiu-se de plantas de mamona da população FCA-UNESP-PB, do programa de melhoramento de mamona da Faculdade de Ciências Agronômicas - UNESP, de Botucatu (SP), as quais foram originadas da cultivar IAC-Guarani. Este trabalho foi realizado no município de Botucatu (SP) (804 metros de altitude, $22^{\circ} 53^{\prime} 09^{\prime \prime} S$; $48^{\circ} 26^{\prime} 42^{\prime \prime} \mathrm{O}$ ) e de São Manuel, SP (709 metros de altitude, 22\%43'52"S; $\left.48^{\circ} 34^{\prime} 14^{\prime \prime} \mathrm{O}\right)$. O solo de Botucatu é classificado como Ni- 
tossolo Vermelho Distroférrico e o de São Manuel, como Latossolo Vermelho-Amarelo Fase Arenosa, de baixa fertilidade natural. O clima de Botucatu (SP), de acordo com a classificação de Köppen, é do tipo Cfa, subtropical, com verôes quentes e úmidos, e invernos frios e secos. O clima de São Manuel (SP) é classificado, segundo a classificação de Köppen, como tipo Cwa, tropical úmido, com inverno seco e verão chuvoso (Köppen, 1948).

A seleção das plantas foi realizada em Botucatu (SP), em condições de safrinha, no ano agrícola de 2007. O experimento foi instalado em época de safrinha, em virtude das condiçốes climáticas que as plantas selecionadas seriam submetidas. A menor ocorrência de chuva na safrinha, em comparação com a safra, é uma vantagem, tendo em vista que o risco de desenvolvimento de doenças como mofo cinzento (Amphobotrys ricini) é minimizado. O mofo cinzento, se ocorrer na fase de emissão da inflorescência, pode afetar o sistema reprodutivo da planta, prejudicando o desenvolvimento da flor; caso ocorra nos frutos formados ou em desenvolvimento, ocasiona danos e perdas de sementes. No presente projeto, perdas de racemos autofecundados inviabilizariam a realização do experimento.

Para o preparo do solo, foi utilizado arado e grade e a adubaçáo, feita de acordo com os dados de análise química do solo, adicionando $400 \mathrm{~kg}$ da formulaçáo 4-14-8 no plantio; na adubação de cobertura foi adicionado $50 \mathrm{~kg}$ de N, na forma de nitrato de amônio.

Foi semeado um campo com 99 linhas de 7,5 m de comprimento e 15 plantas em cada linha, com espaçamento de $1 \mathrm{~m}$ entre linhas e $0,5 \mathrm{~m}$ entre plantas, totalizando1485 plantas. A semeadura foi feita manualmente em 28 de março de 2007, e utilizadas três sementes por cova a uma profundidade de $5 \mathrm{~cm}$. O desbaste foi realizado 27 dias após a semeadura. A irrigação e o controle de plantas daninhas e pragas foram feitos de acordo com a necessidade, ao longo do ciclo. O início do florescimento ocorreu aos 64 dias após a semeadura. A temperatura média do período de cultivo foi de $20,4^{\circ} \mathrm{C}$ e o acúmulo de chuvas de $48,1 \mathrm{~mm}$.

A seleção das plantas realizou-se no início do florescimento, e o critério foi identificar plantas em que havia o racemo primário estritamente feminino. Tais plantas foram marcadas e tiveram seu desenvolvimento acompanhado para observação da expressão sexual dos racemos de $2 .^{\mathrm{a}} \mathrm{e} 3 .^{\mathrm{a}}$ ordens. As plantas que reverteram sexualmente os racemos de $2 .^{\mathrm{a}}$ e $3 .^{\mathrm{a}}$ ordens para o monoicismo (racemos com flores femininas no ápice e masculinas na base) no decorrer do ciclo, foram autofecundadas.

A autofecundação das plantas selecionadas ocorreu quando do início do florescimento, com a proteção da inflorescência nova, com as flores ainda fechadas, e o uso de sacos de papel impermeável. Para evitar a contaminaçáo, os sacos de papel foram retirados somente quando os fru- tos já estavam desenvolvidos. Os racemos autofecundados foram entâo marcados com arames coloridos.

No fim do ciclo de seleção, após maturação dos frutos, foram colhidos separadamente:

- o racemo primário das plantas selecionadas - método de seleção massal (T1);

- os racemos de $2 .^{a}$ e $3 .^{a}$ ordens autofecundados das plantas selecionadas - método de seleção massal com autofecundação (T2);

- os racemos de plantas ao acaso que náo tiveram seleção - testemunha (T3).

As sementes beneficiadas de cada racemo colhido (método de seleção) foram avaliadas no ano agrícola de 2008, em condiçôes de safrinha, em dois locais: na Fazenda Experimental Lageado (Botucatu, SP) e Fazenda Experimental São Manuel (São Manuel, SP). Os dados referentes à altitude, latitude, longitude, tipo de solo e clima são os mesmos citados anteriormente. Em virtude da forte influência ambiental na característica de expressão sexual da mamona, foi realizado o trabalho em locais diferentes, para verificar os possíveis comportamentos diferencias quanto ao aumento de flores femininas no racemo primário.

Os dados de temperatura mínima, máxima e média do ar (graus Celsius) e precipitação pluvial (mm), para os municípios de Botucatu e Sáo Manuel (SP), no período dos experimentos, ou seja, de abril a outubro, foram obtidos do Centro Meteorológico da Faculdade de Ciências Agronômicas, UNESP, e estâo apresentados nas figuras 1 e 2.

As semeaduras foram realizadas manualmente em 8/4/08 e 10/4/08 em Botucatu e Sáo Manuel (SP), respectivamente. Foram comparados três métodos de seleção sob o delineamento experimental de blocos casualizados, com 30 repetiçóes. Cada parcela foi constituída de uma linha com $4 \mathrm{~m}$ de comprimento e 8 plantas por linha, com espaçamento de $1 \mathrm{~m}$ entre linhas e $0,5 \mathrm{~m}$ entre plantas.

O início do florescimento ocorreu 70 dias após a semeadura em Botucatu (SP) e aos 75 dias em São Manuel (SP). As características avaliadas foram:

porcentagem de flores femininas no racemo primário das plantas contidas na área útil da parcela (\%);

produtividade de grãos por parcela de $3,5 \mathrm{~m}^{2}$ com teor de água corrigido a $10 \%\left(\mathrm{~kg} \mathrm{ha}^{-1}\right)$;

- teor de óleo (\%): determinado pela fórmula adaptada de Soxhlet:

$\%$ óleo $=\frac{(\mathrm{M}-\mathrm{m}) \times 100}{\mathrm{M}-\mathrm{c}}$

M (massa da amostra antes da extração $)=$ massa do cartucho + massa do material macerado;

$\mathrm{m}$ (massa da amostra após a extração) = massa do cartucho + massa do material macerado após a extração de óleo;

$\mathrm{c}($ massa do cartucho $)=$ massa do papel filtro + massa dos grampos. 

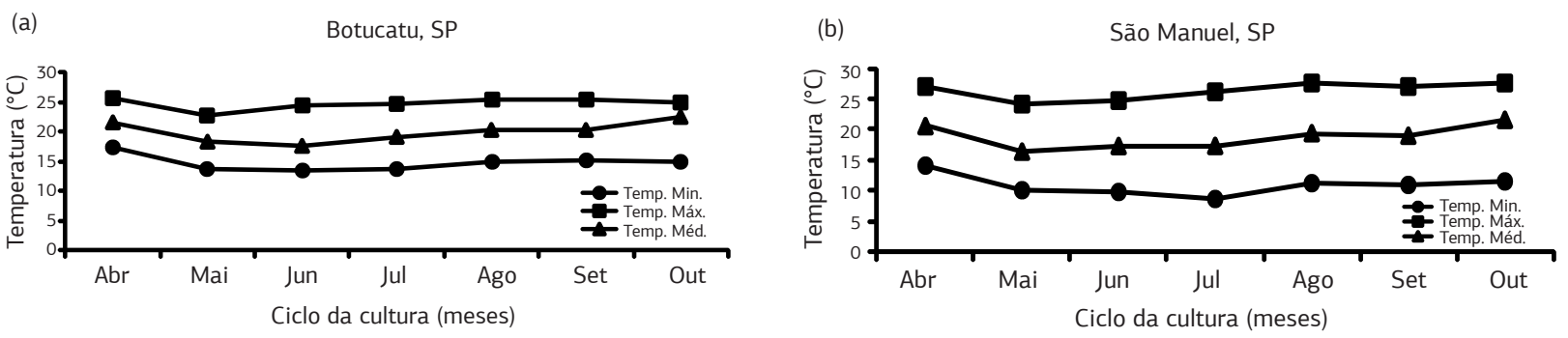

Figura 1. Temperaturas mínima, máxima e média no período de abril a outubro de 2008 nos municípios de Botucatu (a) e São Manuel (b), Estado de São Paulo, referente ao cultivo da safrinha, 2008.
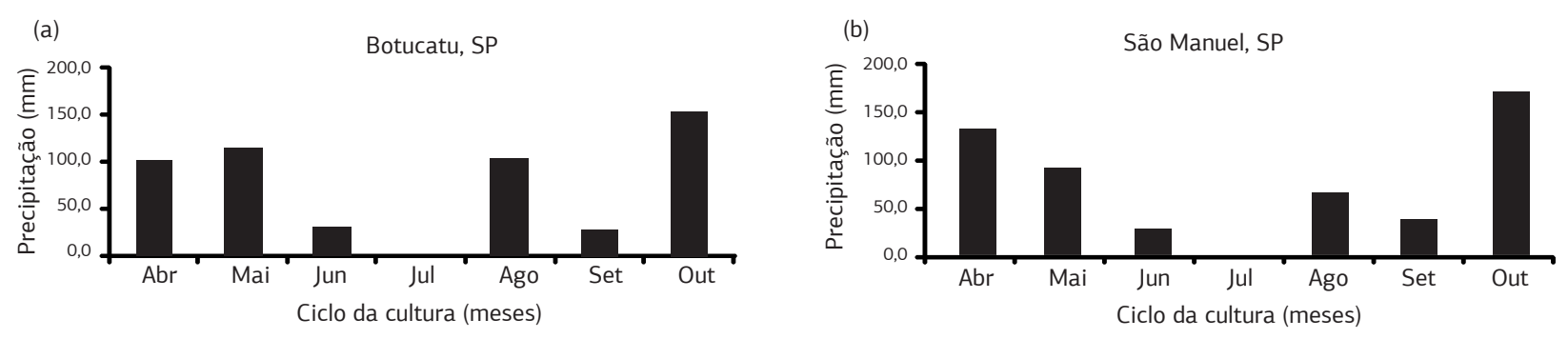

Figura 2. Precipitação pluvial em mm nos municípios de Botucatu (a) e São Manuel (b), Estado de São Paulo, no período de abril a outubro, referente à safrinha de 2008.

A análise de variância foi realizada separadamente para cada local utilizando o teste $\mathrm{F}$, a $1 \%$ de probabilidade, e em virtude da variância homogênea dos quadrados médios do resíduo para os dados individuais dos locais, foi realizada a análise conjunta dos dados, segundo descrito por FonseCA Júnior (1999), utilizando o teste F, a $1 \%$ de probabilidade. Posteriormente foi realizada a comparaçáo das médias por meio do teste de Tukey a 5\% de probabilidade.

Foram estimados os ganhos fenotípicos para a característica porcentagem de flores femininas no racemo primário, através da fórmula:

(Média T2 - Média T3) x 100

Média T3

\section{RESULTADOS E DISCUSSÃO}

A análise de variância individualizada dos dois experimentos (Botucatu e São Manuel, SP) revelou quadrados médios dos erros (QME) com a relação entre o maior e o menor QME, em torno de 4, demonstrando que a variância foi homogênea para o conjunto de dados individuais (FonseCa Júnior, 1999). Portanto, foi realizada a análise conjunta para os dois locais para as características porcentagem de flores femininas, produtividade de grãos e teor de óleo, para verificar se houve interação de métodos de seleção x locais.

$\mathrm{Na}$ tabela 1 está apresentada a análise conjunta para Botucatu e São Manuel (SP), com os quadrados médios e respectivas significâncias pelo teste $\mathrm{F}$ a $1 \%$ de probabilidade, para as características porcentagem de flores femininas no racemo primário $(\mathrm{FF})$, produtividade de grãos $(\mathrm{PG})$ e teor de óleo na semente (TO), na população de mamona FCA-UNESP-PB.

Para a característica porcentagem de flores femininas, observou-se que o quadrado médio da interação métodos de seleção $\mathrm{x}$ locais não foi significativo, mostrando que os métodos de seleção não tiveram comportamento diferencial em relação aos locais, podendo ser comparados em termos médios (Tabela 1). Para a seleção da característica de feminilidade no racemo primário, esses dados são de extrema importância, pois como já relatado, a porcentagem de flores femininas no racemo da mamoneira é fortemente influenciada pelo ambiente. Contudo, no presente trabalho, a expressão da característica foi semelhante para as condiçóes ambientais de Botucatu e São Manuel (SP).

Os quadrados médios para a porcentagem de flores femininas para locais e tratamentos foram significativos (Tabela 1), revelando que houve diferença entre os métodos de seleção.

Observa-se que o coeficiente de variação para a característica porcentagem de flores femininas foi alto $(25,61 \%)$, o que já era previsto, por se tratar de uma característica muito afetada por condiçôes ambientais.

$\mathrm{Na}$ tabela 2 estáo apresentadas as médias dos tratamentos de plantas de mamona da populaçáo FCAUNESP-PB, para a característica porcentagem de flores femininas no racemo primário (FF), dos municípios de Botucatu e São Manuel (SP), na safrinha 2008.

O método seleção massal com autofecundação obteve os maiores valores para a porcentagem de flores femininas no racemo primário, em ambos os locais (Tabela 2), com média dos locais de 42,28\%. Este resultado difere 
Tabela 1. Análise de variância conjunta para os dois locais (Botucatu e São Manuel, SP) para os métodos seleção massal, seleção massal com autofecundação e testemunha, de plantas de mamona (Ricinus communis L.) da população FCA-UNESP-PB, para a característica porcentagem de flores femininas no racemo primário (FF), produtividade de grãos (PG) e teor de óleo na semente (TO), na safrinha 2008

\begin{tabular}{|c|c|c|c|c|}
\hline \multirow{2}{*}{ FV } & \multirow{2}{*}{ G.L. } & \multicolumn{3}{|c|}{ QM } \\
\hline & & FF & PG & TO \\
\hline \multirow[t]{2}{*}{ Blocos } & & $\%$ & $\mathrm{~kg} \mathrm{ha}^{-1}$ & $\%$ \\
\hline & 29 & - & - & - \\
\hline Locais (L) & 1 & $369,80^{*}$ & $1605455,45^{*}$ & $6,033575^{\text {ns }}$ \\
\hline Tratamentos(T) & 2 & $1277,54^{*}$ & $43416,70^{*}$ & 9,97916 ns \\
\hline$T \times L$ & 2 & $22,85^{\mathrm{ns}}$ & $140363,35^{*}$ & $0,819918^{\text {ns }}$ \\
\hline Resíduo Médio & 145 & 90,29 & 11448,51 & 4,133693 \\
\hline Média & & 36,65 & 1541,8 & 45,95 \\
\hline CV (\%) & & 25,61 & 6,94 & 4,42 \\
\hline
\end{tabular}

Tabela 2. Médias dos tratamentos de plantas de mamona (Ricinus communis L.) da população FCA-UNESP-PB, para a característica porcentagem de flores femininas no racemo primário (FF), nos municípios de Botucatu e São Manuel (SP), na safrinha 2008

\begin{tabular}{lc} 
& \multicolumn{1}{c}{ Média } \\
Tratamentos & Botucatu/São Manuel \\
& FF \\
Seleção massal & $\%$ \\
Seleção massal com autofecundação & 35,63 b \\
Testemunha & 42,28 a \\
Média geral & 33,42 b
\end{tabular}

Médias seguidas de mesma letra na vertical não diferem entre si pelo teste de Tukey ao nível de $5 \%$ de probabilidade.

Tabela 3. Média geral dos tratamentos de plantas de mamona (Ricinus communis L.) da população FCA-UNESP-PB, para a característica produtividade de grãos (PG) nos municípios de Botucatu e São Manuel (SP), na safrinha 2008

\begin{tabular}{|c|c|c|}
\hline \multirow{3}{*}{ Tratamentos } & \multicolumn{2}{|c|}{ PG } \\
\hline & Botucatu & São Manuel \\
\hline & \multicolumn{2}{|c|}{$\mathrm{kg} \mathrm{ha}^{-1}$} \\
\hline Seleção massal & $1624,9 \mathrm{a}$ & $1491,8 \mathrm{a}$ \\
\hline Seleção massal com autofecundação & $1661,0 \mathrm{a}$ & $1360,4 \mathrm{~b}$ \\
\hline Testemunha & 1622,8 a & 1489,8 a \\
\hline Média geral & 1623,2 & 1447,3 \\
\hline
\end{tabular}

Médias seguidas de mesma letra na vertical não diferem entre si pelo teste de Tukey ao nível de 5\% de probabilidade.

dos analisados por SHIFRIss (1955), que não observou diferença nas porcentagens de flores femininas dos racemos de mamona, na descendência de racemos autofecundados em comparação com racemos de fecundação cruzada.

Para a característica produtividade de grãos, o quadrado médio da interação de tratamentos por locais foi significativo pelo teste $\mathrm{F}$ a $1 \%$ de probabilidade (Tabela 1). Por meio dos métodos de seleção verificou-se comportamento diferencial em relaçáo aos locais para esta característica, mostrando que não podem ser comparados em termos médios. O quadrado médio para tratamentos e locais também revelou significância pelo teste $\mathrm{F}$, ao nível de $1 \%$ de probabilidade. Os métodos de seleção tiveram valores médios diferentes para a produtividade de grãos, $\mathrm{e}$ os valores médios para locais também diferiram.

Na tabela 3, estáo apresentados os valores médios dos tratamentos e locais para a característica produtividade de grãos. Observou-se que a média de produtividade de grãos não diferiu entre os tratamentos no experimento de Botucatu (SP); entretanto, no município de São Manuel (SP), a produtividade de grãos foi reduzida no método seleção massal com autofecundação, quando comparadas com a seleção massal e a testemunha. A menor produtividade de grãos $\left(1360,4 \mathrm{~kg} \mathrm{ha}^{-1}\right)$ para o método com autofecundaçáo pode ser entendida como resposta à depressão endogâmica causada por autofecundações. Entretanto, Gurgel (1945), estudando a genética de diversas características em mamoneira, afirmou que não ocorre depressão endogâmica em mamoneira. Como a menor produtividade apresentada para o método de seleção massal com autofecundação ocorreu somente no município de São Manuel (SP) pode-se também inferir que foi decorrente das condiçôes ambientais, já que ocorrem diferenças na taxa de cruzamento, em virtude da variação na direção e intensidade dos ventos, bem como da umidade relativa do ar. 
Na tabela 1, pode ser observado que o quadrado médio da interaçáo entre os tratamentos por locais para a característica teor de óleo náo foi significativo (a 1\% e a $5 \%$ de probabilidade), pelo teste $\mathrm{F}$, o que evidenciou a inexistência de comportamento diferencial entre os métodos em relação aos locais. Os quadrados médios para tratamentos e para locais também não tiveram significância.

A ausência de diferença significativa entre os tratamentos para a característica teor de óleo é fator importante do ponto de vista de seleção de genótipos com maior teor de óleo. Não foi verificado queda nos valores de teor de óleo das sementes (depressão endogâmica) quando as plantas de mamona foram submetidas à autofecundação, declínio observado para a característica produtividade de gráos. Os resultados sáo importantes, pois se verifica que a seleção de plantas de mamona com maior porcentagem de flores femininas não influenciou a característica teor de óleo nas sementes. A média geral dos tratamentos para teor de óleo foi de 45,95\%.

Os resultados de ganhos fenotípicos realizado para a característica porcentagem de flores femininas no racemo primário tiveram o valor de $18 \%$ no município de Botucatu, (SP) com o método de seleção massal com autofecundação em relação à testemunha. Em São Manuel (SP) o ganho foi superior chegando a $29 \%$. O parâmetro de ganho fenotípico exprime o avanço da geração seguinte em relação à população original, decorrente da seleção efetuada.

No município de São Manuel (SP) os resultados foram mais favoráveis em relação à porcentagem de flores femininas na seleção massal com autofecundação do que em Botucatu (SP). Acredita-se que essa diferença tenha ocorrido em virtude das diferenças ambientais locais dos municípios.

As figuras 3 e 4 representam as distribuiçóes das frequências de plantas de mamona com as respectivas porcentagens de flores femininas no racemo primário dos tratamentos. Em relação à porcentagem de plantas 100\% femininas, foi obtida no município de Botucatu (SP) uma média de 2,5\% com o método seleção massal, 1,25\% na

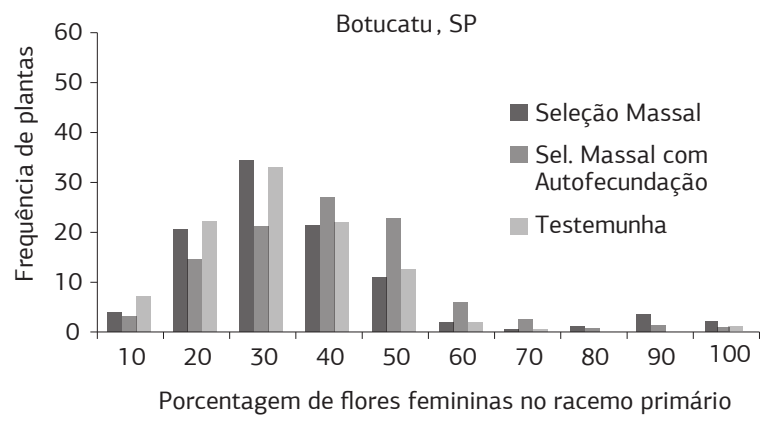

Figura 3. Frequência de plantas de mamona (Ricinus communis L.) da população FCA-UNESP-PB com as respectivas porcentagens de flores femininas no racemo primário, resultantes dos métodos de seleção massal, seleção massal com autofecundação e testemunha, no município de Botucatu (SP). seleção massal com autofecundação, e $0,83 \%$ na testemunha (Figura 3). Em São Manuel, (SP) as médias foram de $6 \%$ no método seleção massal, $6 \%$ para seleção massal com autofecundaçáo e $0 \%$ na testemunha (Figura 2). Este resultado está de acordo com as observações de SHIFriss (1955) que constatou diferenças significativas em relação à porcentagem de plantas femininas nas progênies quando utilizou o método da polinização de racemos $100 \%$ femininos com pólen de plantas monóicas (sib polinization) e o método da autofecundaçáo de racemos. MYCzKowski (2006), também trabalhando com a população FCAUNESP-PB, obteve uma frequência de $7,9 \%$ de plantas com o racemo $100 \%$ pistilado, resultando bastante semelhante ao avaliados neste trabalho, no município de São Manuel, SP (Figura 4).

A frequência de plantas com $10 \%$ e $20 \%$ de flores femininas no município de Botucatu (SP) foi de 0,6\% e $12 \%$, respectivamente (Figura 3). No município de São Manuel (SP), a frequência de plantas com $10 \%$ e $20 \%$ de flores femininas foi de 3\% e 14\% respectivamente (Figura 4). Plantas com racemo de até $40 \%$ de flores femininas não diferem das plantas com racemos monóicos normais, e essa porcentagem de flor feminina não é a ideal em termos de melhoramento genético.

As plantas com frequência entre $50 \%$ e $90 \%$ de flores femininas são interessantes, desde que seja realizada maior pressão de seleçáo, sendo necessários mais ciclos de seleção e autofecundação para a expressão da característica pistilada. Sabe-se que seleção contínua é fundamental para o caráter de feminismo, pois a tendência da planta de mamona é retornar ao monoicismo.

Dentre as plantas selecionadas em 2007 náo foi constatada nenhuma feminina geneticamente estável, ou seja, todas tiveram reversão sexual para o monoicismo; algumas passaram a apresentar flores estaminadas logo após a emissão do racemo primário, outras demoraram um pouco mais, mas todas reverteram antes da emissão do décimo racemo, que pode ser denominada como "reversão precoce", segundo SHIFRIss (1955).

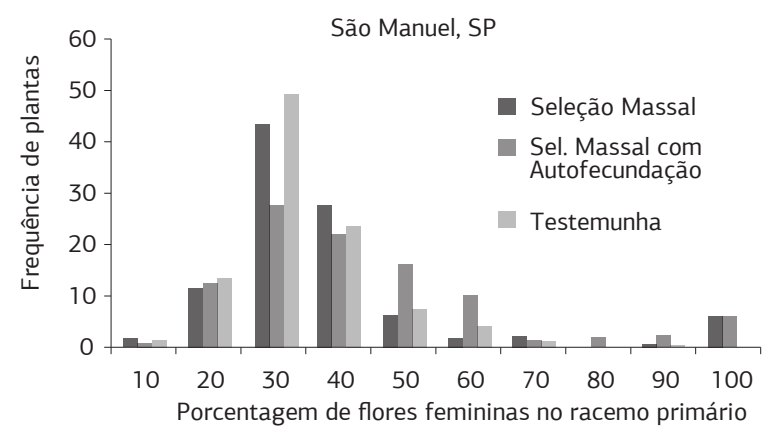

Figura 4. Frequência de plantas de mamona (Ricinus communis L.) da população FCA-UNESP-PB com as respectivas porcentagens de flores femininas no racemo primário, resultantes dos métodos de seleção massal, seleção massal com autofecundação e testemunha, no município de São Manuel (SP). 
A herança da característica pistilada em mamoneira é extremamente complexa. Shifriss (1960) afirma que os resultados de seus experimentos foram pouco conclusivos e não permitiram qualquer interpretação mendeliana.

Mediante os resultados deste trabalho, nota-se a necessidade de continuidade por meio de ciclos de seleção contínuos e maior pressão de seleção, a fim de manter a característica de racemos com alta porcentagem de flores femininas.

\section{CONCLUSÃO}

O método da seleção massal com autofecundação de racemos de plantas $100 \%$ femininas com reversão sexual, retornando ao monoicismo, é o mais eficiente no aumento da porcentagem de flores femininas em plantas de mamona (Ricinus communis L.) da população FCA-UNESP-PB.

\section{REFERÊNCIAS}

BANZATTO, N.V.; ROCHA, J.L.V. DA R. Genética e melhoramento da mamoneira. In: KERR, W.E. (Ed.). Melhoramento e genética. São Paulo: Editora da Universidade de São Paulo, 1969. p.02-113.

BELTRÃO, N.E. DE M.; SILVA, L.C.; VASCONCELOS, O.L.; AZEVEDO, D.M.P. DE; VIEIRA, D.J. Fitologia. In: AZEVEDO, D.M.P. DE; LIMA, E.F. (Ed.). O agronegócio da mamona no Brasil. Campina Grande: Embrapa Algodão; Brasília: Embrapa Informação Tecnológica, 2001. p.37-62.

CLAASSEN, C.E.; HOFFMAN, A. The inheritance of the pistillate character in castors and its possible utilization in the production of commercial hybrid seed. Agronomy Journal, v.42, p.79-82, 1949.
FONSECA JÚNIOR, N. DA S. Interação genótipo x ambiente: aspectos biométricos. In: DESTRO, D.; MONTALVÁN, R. (Ed.). Melhoramento genético de plantas. Londrina: Uel-Londrina, 1999. p.141-178.

GRIFFITHS, A.J.F.; MILLER, J.H.; SUZUKI, D.T.; LEWONTIN, R.C.; GELBART, W.M. Introdução à genética. 7. ed. Rio de Janeiro: Guanabara Koogan, 2000. 794p.

GURGEL, J.T.A. Estudos sobre a mamoneira (Ricinus communis L.). 1945. 69f. Tese (Doutorado em Citologia e Genética Geral) Escola Superior de Agricultura Luiz de Queiroz, Piracicaba.

KÖPPEN, W. Climatologia: con un estudio de los climas de la tierra. México: Fondo de Cultura Econômica, 1948. 479p.

MYCZKOWSKI, M.L. Seleção para aumento da porcentagem de flores femininas na população FCA-UNESP-PB de mamona (Ricinus communis L.). 2006. 33f. Tese (Doutorado em Agronomia - Agricultura) - Faculdade de Ciências Agronômicas, Universidade Estadual Paulista, Botucatu.

SHIFRISS, O. Sex instability in Ricinus. Genetics, v.41, p.265280, 1955.

SHIFRISS, O. Conventional and unconventional systems controlling sex variations in Ricinus. Journal of Genetics, v.57, p.361-388, 1960 .

TÁVORA, F.J.A. A cultura da mamona. Fortaleza: EPACE, 1982. $111 \mathrm{p}$.

VENCOVSKY, R.; PEREIRA, M.B.; CRISÓSTOMO, J.R.; FERREIRA, M.A.J. Genética e melhoramento de populaçôes mistas. In: NASS, L.L.; VALOIS, A.C.C.; MELO, I.S.; VALADARESINGLIS, M.C. Recursos genéticos e melhoramento de plantas. Rondonópolis: Fundação MT, 2001. p.231-281.

WEISS, E.A. Castor. In: WEISS, E.A. (Ed.). Oilseed crops. London: Longman, 1983. 660p. 